\title{
Comparison of the Effectiveness of Halofuginone Lactate and Paromomycin in the Treatment of Calves Naturally Infected with Cryptosporidium parvum
}

\author{
Ugur Aydogdu' ${ }^{1}$ Nermin Isik², Ozlem Derinbay Ekici², Ramazan Yildiz ${ }^{3}$, Ismail Sen ${ }^{4,5}$ \& Alparslan Coskun ${ }^{6}$
}

\begin{abstract}
Background: Cryptosporidiosis is one of the most important problems among neonatal ruminants. Cryptosporidium parvum is the agent causing the disease. Cryptosporidium infection, responsible for diarrhea, dehydration, weight loss and death in neonatal ruminants, leads to significant economic losses for producers. In calves naturally or experimentally infected with cryptosporidiosis, many agents have been reported to have therapeutic and protective effects. The objective of this study was to compare the effectiveness of halofuginone lactate and paromomycin in the treatment of calves naturally infected with Cryptosporidium parvum.

Materials, Methods \& Results: Twenty calves between 7 and 20 days of age and naturally infected were included in the study. There were two different treatment groups in the study. The first group of calves were administered $100 \mu \mathrm{g} / \mathrm{kg} / \mathrm{day}$ halofuginone lactate for 7 days and the second group of calves were administered $100 \mathrm{mg} / \mathrm{kg} / \mathrm{day}$ paromomycin for 7 days. In addition, antibiotic and vitamin $\mathrm{C}$ were applied to all calves. Jugular venous blood samples were obtained pre-treatment and on the $7^{\text {th }}$ day after the treatment. Routine clinical examinations of the calves were performed on days $0,1,3,5$ and 7 and rectal stool samples were collected for the detection of Cryptosporidium oocysts. Severe diarrhea, dehydration, depression and weight loss were observed in calves in both treatment groups. A significant decrease $(P<0.05)$ was observed for both groups in oocyst count on days 3, 5 and 7 compared to days 0 and 1 . Improvements in blood parameters, stool characters and clinical scoring of both groups were observed in post-treatment.

Discussion: Many pharmaceuticals or compounds have been tested for animal with cryptosporidiosis and only very few of them have shown a partial protective activity in ruminants when used prophylactically. Halofuginone lactate and paromomycin are commonly recommended as both therapeutic and protective agents. However, the effectiveness of the two therapeutic agents in natural infections has not been compared and, in the meantime, recommendations for a rational use are also not sufficiently documented in calves with cryptosporidiosis. Paromomycin is an aminoglycoside antibiotic used to control C. parvum infection in animals. Paromomycin reduces oocyst shedding and the number of days with diarrhea in experimentally infected calves when used prophylactically. Halofuginone lactate is a synthetic quinazolinone with cryptosporidial activity in the merozoite and sporozoite stages of $C$. parvum. It is recommended for both therapeutic and prophylactic use in cryptosporidiosis. In this study, although paromomycin $(100 \mathrm{mg} / \mathrm{kg} / \mathrm{day}$ for 7 days $)$ and halofuginone lactate (100 $\mu \mathrm{g} / \mathrm{kg} /$ day for 7 days) led to a decrease in oocyst shedding from day 1 , a statistically significant decrease $(P<0.05)$ was observed from day 3 . The results of this study show that the decrease in oocyst shedding in both treatment groups, improvements in clinical findings and recoveries in hematologic, blood gas and serum biochemistry values are similar. Even though these drugs do not eliminate the infection, they decrease both the severity of diarrhea and contribute to recovery. In conclusion, the results of this study indicated that halofuginone lactate and paromomycin were effective in the treatment of calves naturally infected with cryptosporidiosis. Therefore, we recommend that both drugs should be used in the treatment of calves naturally infected with Cryptosporidium parvum.
\end{abstract}

Keywords: cryptosporidiosis, calves, paromomycin, halofuginone lactate.

${ }^{1}$ Department of Internal Medicine, Faculty of Veterinary Medicine, Balikesir University, Balikesir, Turkey. ${ }^{2}$ Department of Parasitology, Faculty of Veterinary Medicine, Selcuk University, Konya, Turkey. ${ }^{3}$ Department of Internal Medicine, Faculty of Veterinary Medicine, Mehmet Akif Ersoy University, Burdur, Turkey. ${ }^{4}$ Department of Internal Medicine, Faculty of Veterinary Medicine, Selcuk University, Konya. ${ }^{5}$ Department of Internal Medicine, Faculty of Veterinary Medicine, Near East University, Nicosia, Cyprus. ${ }^{6}$ Department of Internal Medicine, Faculty of Veterinary Medicine, Cumhuriyet University, Sivas, Turkey. CORRESPONDENCE: A. Coskun [acoskun@ cumhuriyet.edu.tr - Fax: +90 346 2191812] Department of Internal Medicine, Faculty of Veterinary Medicine, Cumhuriyet University. 58140 Sivas, Turkey. 


\section{INTRODUCTION}

Cryptosporidiosis, which causes neonatal diarrhea, has a high prevalence disease throughout the world $[4,7,25]$. Clinical cryptosporidiosis is observed in calves of 7-30 days old and continues for 4-17 days. The calves with diarrhea are usually lethargic, anorexic and dehydrated. High fever and straining may also be observed. While variable morbidity is reported, the mortality rate is low. The severity of the disease may vary depending on other pathogens and co-infections. In severe cases, death may be seen due to dehydration and cardiovascular collapse $[6,9,25]$.

In calves naturally or experimentally infected with Cryptosporidium parvum, many agents have been reported to have therapeutic and protective effects. However, only two of these agents, halofuginone lactate and paromomycin, have been licensed for calves in some countries. Halofuginone is a plant alcaloid isolated from Dichroa febrifuga and synthetically produced [23]. It has been reported that it is effective on cryptosporidiosis. It shows this effect on the merozoite and sporozoite stages of $C$. parvum $[10,14]$. Halofuginone lactate reduces the severity of cryptosporidiosis, delays the start of infection and reduces oocyst shedding, and is recommended for calves as a therapeutic and protective agent $[3,10,11,13,14]$. Paromomycin, another effective drug, is a large-spectrum antibiotic in the aminoglycosides group produced by Streptomyces rimosus var. paromomycinus. Unlike other aminoglycosides, it has gram-positive and gram-negative activity. Paromomycin has a weak absorption from the gastrointestinal region. This provides an advantage when used for the treatment of certain bacterial and protozoan infections of the gastrointestinal system [8]. Studies have shown that paromomycin is highly effective in prophylaxis and causes no toxicity in calves, lambs and goats naturally and experimentally infected with $C$. parvum $[5,15,28]$.

Halofuginone lactate and paromomycin are commonly recommended as both therapeutic and protective agents. The effectiveness of these two drugs on natural infections has not been compared and the information on their rational use is not sufficient. The aim of this study is to compare the effectiveness of halofuginone lactate and paromomycin in the treatment of calves naturally infected with cryptosporidiosis and to demonstrate the clinical recovery status during the treatment process.

\section{MATERIALS AND METHODS}

\section{Animals and experimental procedure}

This study was conducted with 20 calves aged 7-20 days with diarrhea, diagnosed as having C. parvum. It was carried out in the Farm Animal Clinic of the Faculty of Veterinary Medicine of Selcuk University. The calves were divided randomly into two groups according to the drug administered. The first group of calves $(\mathrm{n}=10)$ were administered $100 \mu \mathrm{g} / \mathrm{kg} /$ day halofuginone lactate $\left(\text { Halocur }^{\circledR}\right)^{1}$ for 7 days and the second group of calves $(n=10)$ were administered $100 \mathrm{mg} / \mathrm{kg}$ /day paromomycin (Gabbro$\left.\mathrm{col}^{\circledR}\right)^{2}$ for 7 days. All calves included in the study were administered fluid therapy depending on dehydration degree and base deficit level, $16 \mathrm{mg} \mathrm{kg}^{-1}$ intramuscular sulfadoxine+trimethoprim $\left(\text { Animar }^{\circledR}\right)^{2}$ injection once a day for 7 days and $1000 \mathrm{mg}$ vitamin $\mathrm{C}$ (Injacom $\left.\mathrm{C}^{\circledR}\right)^{2}$ injection once a day for 7 days. Eight of the calves in the first group were Holstein, 1 was Simmental and 1 was Norwegian Red, whereas all calves in the second group were Holstein.

Blood sampling

Blood samples for blood gas, hematological and biochemical analyses were taken from jugular vein pre-treatment (day 0) and on 7th day after the treatment. Blood gas and hematological samples were analyzed within $15 \mathrm{~min}$ after the blood collection. Tubes without anticoagulants were left for coagulation at room temperature for $30 \mathrm{~min}$ and centrifuged at $2500 \mathrm{~g}$ for $10 \mathrm{~min}$ and serums were removed and kept at $-20^{\circ} \mathrm{C}$ until the analysis.

\section{Hematological, biochemical and blood gas analyses}

Blood white blood cell (WBC), red blood cell (RBC), hematocrit (Hct), hemoglobin $(\mathrm{Hg})$ and platelet (PLT) levels of calves were determined using hematological analyzer (MS4VET) ${ }^{3}$. Blood $\mathrm{pH}$, $\mathrm{pO}_{2}, \mathrm{pCO}_{2}$, glucose, sodium $\left(\mathrm{Na}^{+}\right)$, potassium $\left(\mathrm{K}^{+}\right)$, lactate, base excess $(\mathrm{BE})$, bicarbonate $\left(\mathrm{HCO}^{3-}\right)$ and oxygen saturation $\left(\mathrm{O}_{2}\right.$ SAT) levels were determined using a blood gas analyzer (GEM Premier Plus) ${ }^{4}$. Serum blood urea nitrogen (BUN), creatinine, aspartate aminotransferase (AST), gamma glutamyl transferase (GGT), alkaline phosphatase (ALP), total protein and albumin concentrations of calves were determined using commercial kits and an autoanalyzer (BS-200) . 


\section{Clinical examination and stool sampling}

Routine clinical examinations of calves were performed on days $0,1,3,5$ and 7 and rectal stool samples were collected using plastic stool containers for the detection of Cryptosporidium oocysts.

\section{Determination of Cyptosporidium parvum oocysts}

Stool samples were spread onto plates containing isotonic $\mathrm{NaCl}$ solution and dried at room temperature. Dried preparations were fixed in methyl alcohol for $1 \mathrm{~min}$ and stained with basic fuchsin solution (4 $\mathrm{g}$ basic fuchsin, $20 \mathrm{~mL} \mathrm{95 \%} \mathrm{ethanol,} 8 \mathrm{~mL}$ melted crystal phenol and $100 \mathrm{~mL}$ distilled water) for $4 \mathrm{~min}$. Preparations were rinsed in 50\% ethyl alcohol and washed in tap water for 3-5 s. They were decolorized with $1 \%$ sulphuric acid for 2 min and washed in tap water. After staining with methylene blue for $1 \mathrm{~min}$, they were washed in tap water once more and dried.

\section{Evaluation of preparations}

Immersion oil was used to examine the stained preparations under microscope with a magnification of $100 \times$. The number of oocysts in 20 different randomly selected microscope fields were taken into account for each preparation. Oocyst count (scoring) was assessed as follows: no oocysts: negative (-); a single oocyst in a few fields: rare $(+)$; $1-5$ oocysts: low $(++) ; 6-10$ oocysts: moderate $(+++) ;>10$ oocysts: high $(++++)$.

\section{Statistical analysis}

The data were expressed as mean and standard error of the mean (Mean \pm SEM). The ANOVA multiple range test was used to determine the difference within groups during the treatment process. The Paired-samples t test was used to determine the differences between pre-treatment and post-treatment hematological, blood gas and biochemical parameters. The difference between the two groups was determined using the independent $t$ test. The statistical significance level was accepted to be $P<0.05$.

\section{RESULTS}

\section{Clinical findings}

The scoring was performed according to the criteria for clinical examination findings (body temperature, respiratory rate, pulse, capillary refill time, dehydration degree, conjunctiva status, appetite, mental status, posture and stool property) given in Table 1 and changes in clinical scoring throughout the treatment are given in Figure 1.

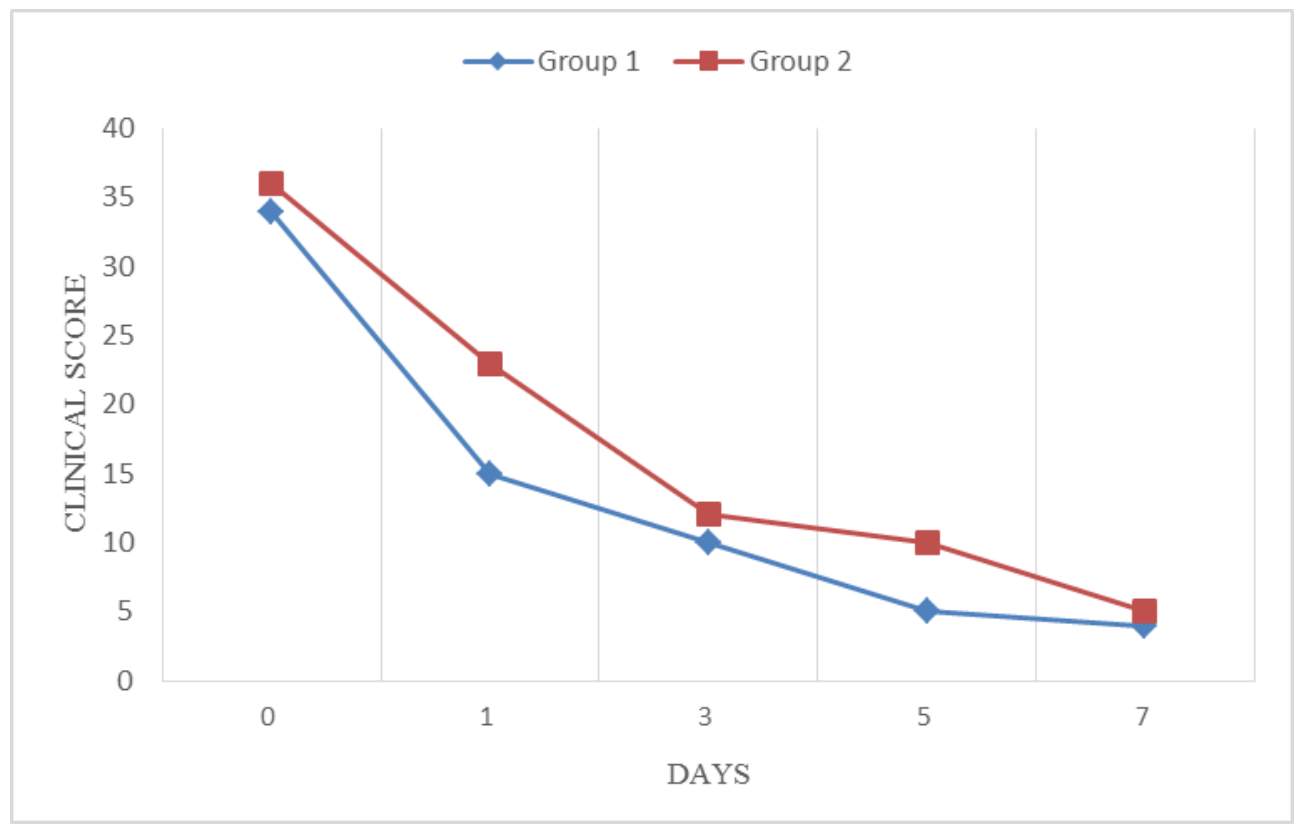

Figure 1. Changes in clinical scoring of calves with cryptosporidiosis before and during the treatment. 
Table 1. Clinical scoring table for calves with cryptosporidiosis.

\begin{tabular}{cccccccc}
\hline Clinical Score & T $\left({ }^{\circ} \mathrm{C}\right)$ & $\begin{array}{c}\text { DD } \\
(\%)\end{array}$ & $\begin{array}{c}\text { CRT } \\
(\mathrm{sec})\end{array}$ & Mucosa & Suckle reflex & Mental Status & $\begin{array}{c}\text { Fecal } \\
\text { character }\end{array}$ \\
\hline 0 & $38-39.5$ & No & $1-2$ & Normal & Normal & Normal & Normal \\
1 & $39.6-40$ & $4-6$ & $3-4$ & Hyperemic & Reluctant & Slightly Depressive & Mild Water \\
2 & $40.1-41$ & $8-10$ & $5-6$ & Pale & Poor & Depressive & Watery \\
3 & $<38$ or $>41$ & $>10$ & $\geq 7$ & Cyanosis & Absent & Unconsciousness & Very watery \\
\hline
\end{tabular}

T: temperature; DD: The degree of dehydration; CRT: Capillary refill time.

\section{Oocyst shedding}

Changes in oocyst shedding of calves in the study on day 0 , and days 1, 3, 5 and 7 after the treatment are given in Figure 2. There was a significant decrease $(P<0.05)$ in both groups in oocyst shedding on days 3,5 and 7 , compared to days 0 and 1 .

\section{Hematological analysis}

Changes in the hematological parameters of calves before (day 0) and after the treatment (day 7) are given in Table 2. Although certain changes in parameters were observed in both groups between day 0 and day 7 , there was no statistically significant change $(P<0.05)$. In terms of differences within the groups, a significant decrease $(P<0.05)$ in the WBC, RBC, Hb and Hct values of the first group was observed on day 7 , compared to day 0 . However, there was a significant increase $(P<0.05)$ in the PLT level of the second group on day 7 , compared to day 0 .

\section{Blood gas analysis}

Changes in the hematological parameters of calves on day 0 and day 7 are given in Table 3 . A significant difference $(P<0.05)$ was determined between the groups in the $\mathrm{K}^{+}$level only. In terms of differences within groups, a significant increase $(P<0.05)$ was found in $\mathrm{pH}, \mathrm{pCO}_{2}, \mathrm{Na}^{+}, \mathrm{HCO}^{3-}$ and $\mathrm{BE}$ levels and a significant decrease $(P<0.05)$ was found in $\mathrm{pO}_{2}, \mathrm{~K}^{+}$and lactate levels for the first group on day 7 compared to day 0 . A significant increase $(P<0.05)$ was found in the $\mathrm{Na}^{+}$level and a significant decrease $(P<0.05)$ was found in the glucose level for the second group on day 7 compared to day 0 .

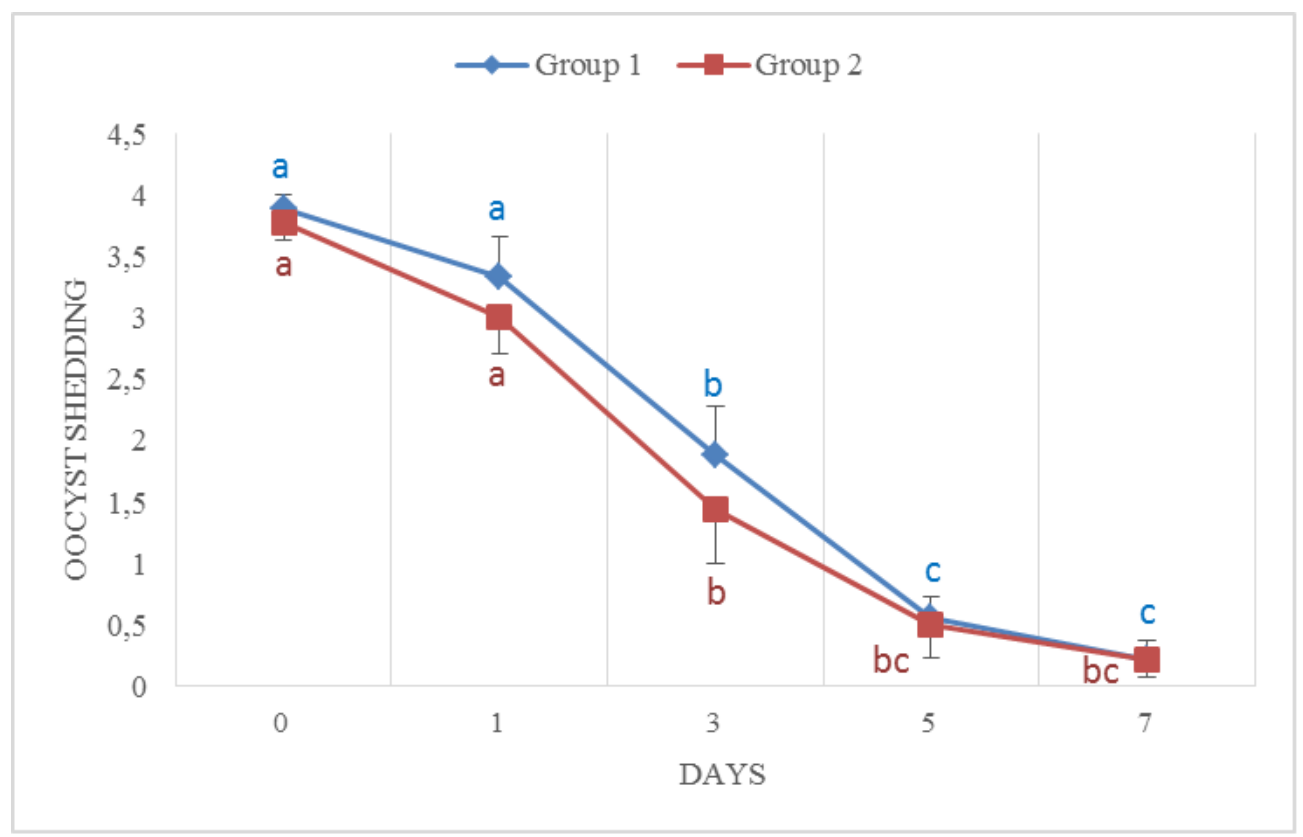

Figure 2. Changes in oocyst shedding of calves with cryptosporidiosis before and during the treatment. a,b,c Within groups statistical significant. 
Table 2. Changes in hematological parameters of calves with cryptosporidiosis before and during the treatment.

\begin{tabular}{|c|c|c|c|c|}
\hline Parameter & $\begin{array}{c}\text { Day } 0 \\
\text { Mean } \pm \text { SEM }\end{array}$ & $\begin{array}{c}\text { Day } 7 \\
\text { Mean } \pm \text { SEM }\end{array}$ & $P^{1}$ & $P^{2}$ \\
\hline \multicolumn{5}{|l|}{ WBC $\left(10^{3} / \mu \mathrm{L}\right)$} \\
\hline Group $1(\mathrm{n}=10)$ & $12.22 \pm 0.98$ & $9.39 \pm 0.54$ & $<0.05$ & \multirow{2}{*}{$>0.05$} \\
\hline Group $2(n=10)$ & $9.97 \pm 1.74$ & $11.02 \pm 2.09$ & $>0.05$ & \\
\hline \multicolumn{5}{|l|}{$\mathrm{RBC}\left(10^{6} / \mu \mathrm{L}\right)$} \\
\hline Group $1(n=10)$ & $8.38 \pm 0.51$ & $7.24 \pm 0.65$ & $<0.05$ & \multirow{2}{*}{$>0.05$} \\
\hline Group $2(n=10)$ & $7.38 \pm 0.38$ & $6.93 \pm 0.44$ & $>0.05$ & \\
\hline \multicolumn{5}{|l|}{$\mathrm{HB}(\mathrm{g} / \mathrm{dL})$} \\
\hline Group $1(\mathrm{n}=10)$ & $10.30 \pm 0.69$ & $8.73 \pm 0.72$ & $<0.05$ & \multirow{2}{*}{$>0.05$} \\
\hline Group $2(n=10)$ & $9.04 \pm 0.59$ & $8.53 \pm 1.06$ & $>0.05$ & \\
\hline \multicolumn{5}{|l|}{$\mathrm{HT}(\%)$} \\
\hline Group $1(\mathrm{n}=10)$ & $29.59 \pm 1.71$ & $24.51 \pm 2.36$ & $<0.05$ & \multirow{2}{*}{$>0.05$} \\
\hline Group $2(n=10)$ & $26.43 \pm 2.10$ & $25.44 \pm 2.76$ & $>0.05$ & \\
\hline \multicolumn{5}{|l|}{ PLT $\left(10^{3} / \mu \mathrm{L}\right)$} \\
\hline Group $1(\mathrm{n}=10)$ & $467.44 \pm 55.85$ & $696.67 \pm 254.16$ & $>0,05$ & \multirow{2}{*}{$>0,05$} \\
\hline Group $2(n=10)$ & $429.50 \pm 50.48$ & $599.80 \pm 93.70$ & $<0,05$ & \\
\hline
\end{tabular}

WBC: white blood cell; RBC: red blood cell; Hb: hemoglobin; Hct: hematocrit; PLT platelet. $P^{\mathrm{l}}=$ Statistically significant $P$ value within groups; $P^{2}=$ Statistically significant $P$ value between groups.

Table 3. Changes in blood gas parameters of calves with cryptosporidiosis before and during the treatment.

\begin{tabular}{|c|c|c|c|c|}
\hline Parameter & $\begin{array}{c}\text { Day } 0 \\
\text { Mean } \pm \text { SEM }\end{array}$ & $\begin{array}{c}\text { Day } 7 \\
\text { Mean } \pm \text { SEM }\end{array}$ & $P^{1}$ & $P^{2}$ \\
\hline \multicolumn{5}{|l|}{$\mathrm{pH}$} \\
\hline Group $1(n=10)$ & $7.33 \pm 0.03$ & $7.42 \pm 0.01$ & $<0.05$ & \multirow{2}{*}{$>0.05$} \\
\hline Group $2(n=10)$ & $7.34 \pm 0.04$ & $7.40 \pm 0.02$ & $>0.05$ & \\
\hline \multicolumn{5}{|l|}{$\mathrm{pCO}_{2}(\mathrm{~mm} \mathrm{Hg})$} \\
\hline Group $1(n=10)$ & $37.89 \pm 1.72$ & $47.11 \pm 2.11$ & $<0.05$ & \multirow{2}{*}{$>0.05$} \\
\hline Group $2(n=10)$ & $41.67 \pm 2.41$ & $43.71 \pm 3.46$ & $>0.05$ & \\
\hline \multicolumn{5}{|l|}{$\mathrm{pO}_{2}(\mathrm{~mm} \mathrm{Hg})$} \\
\hline Group $1(n=10)$ & $27.67 \pm 2.08$ & $24.11 \pm 2.06$ & $<0.05$ & \multirow{2}{*}{$>0.05$} \\
\hline Group $2(n=10)$ & $24.44 \pm 2.90$ & $25.29 \pm 2.00$ & $>0.05$ & \\
\hline \multicolumn{5}{|l|}{$\mathrm{Na}^{+}(\mathrm{mmol} / \mathrm{L})$} \\
\hline Group $1(n=10)$ & $125.22 \pm 2.46$ & $139.00 \pm 1.36$ & $<0.05$ & \multirow{2}{*}{$>0.05$} \\
\hline Group $2(n=10)$ & $131.78 \pm 2.20$ & $138.71 \pm 1.38$ & $<0.05$ & \\
\hline \multicolumn{5}{|l|}{$\mathrm{K}^{+}(\mathrm{mmol} / \mathrm{L})$} \\
\hline Group $1(n=10)$ & $5.20 \pm 0.36$ & $4.08 \pm 0.10$ & $<0.05$ & \multirow{2}{*}{$<0.05$} \\
\hline Group $2(n=10)$ & $4.23 \pm 0.15$ & $4.03 \pm 0.20$ & $>0.05$ & \\
\hline \multicolumn{5}{|l|}{ Glucose (mg/dL) } \\
\hline Group $1(n=10)$ & $84.89 \pm 6.24$ & $82.89 \pm 6.69$ & $>0.05$ & \multirow{2}{*}{$>0.05$} \\
\hline Group $2(n=10)$ & $86.56 \pm 5.88$ & $67.29 \pm 11.03$ & $<0.05$ & \\
\hline \multicolumn{5}{|l|}{ Lactate $(\mathrm{mmol} / \mathrm{L})$} \\
\hline Group $1(n=10)$ & $1.47 \pm 0.22$ & $0.76 \pm 0.13$ & $<0.05$ & \multirow{2}{*}{$>0.05$} \\
\hline Group $2(n=10)$ & $1.11 \pm 0.15$ & $0.84 \pm 0.27$ & $>0.05$ & \\
\hline \multicolumn{5}{|l|}{$\mathrm{HCO}_{3}^{-}(\mathrm{mmol} / \mathrm{L})$} \\
\hline Group $1(n=10)$ & $20.6 \pm 2.05$ & $30.57 \pm 1.70$ & $<0.05$ & \multirow{2}{*}{$>0.05$} \\
\hline Group $2(n=10)$ & $24.69 \pm 3.11$ & $27.46 \pm 2.70$ & $>0.05$ & \\
\hline \multicolumn{5}{|l|}{$\mathrm{BE}(\mathrm{mmol} / \mathrm{L})$} \\
\hline Group $1(n=10)$ & $-4.89 \pm 2.21$ & $5.38 \pm 1.66$ & $<0.05$ & \multirow{2}{*}{$>0.05$} \\
\hline Group $2(n=10)$ & $-2.23 \pm 3.24$ & $2.59 \pm 2.96$ & $>0.05$ & \\
\hline \multicolumn{5}{|l|}{$\mathrm{O}_{2}$ SAT $(\%)$} \\
\hline Group $1(n=10)$ & $46.11 \pm 5.43$ & $43.56 \pm 4.96$ & $>0.05$ & \multirow{2}{*}{$>0.05$} \\
\hline Group $2(n=10)$ & $37.78 \pm 5.60$ & $45.14 \pm 4.49$ & $>0.05$ & \\
\hline
\end{tabular}

$\mathrm{pH}$ : concentration of hydrogen ions; $\mathrm{pCO}_{2}:$ partial pressure of carbon dioxide; $\mathrm{pO}_{2}:$ partial pressure of oxygen; $\mathrm{Na}^{+}$: sodium; $\mathrm{K}^{+}$: potassium; $\mathrm{HCO}^{3-}$ : bicarbonate; BE: base excess; $\mathrm{O}_{2} \mathrm{SAT}$. \%: oxygen saturation. $P^{1}=$ Statistically significant $P$ value within groups; $P^{2}=$ Statistically significant $P$ value between groups. 


\section{Serum biochemical analysis}

Changes in serum BUN, creatinine, AST, GGT, ALP, total protein and albumin concentrations of calves before (day 0 ) and after the treatment (day 7 ) are given in Table 4. While no statistically significant difference was observed between the groups on day 0 and day 7 in serum BUN, creatinine, GGT, total protein and albumin concentrations, a significant difference $(P<$
0.05) was found between day 0 ALP levels and day 7 AST levels. In terms of differences within groups, a significant decrease $(P<0.05)$ was found in BUN, creatinine, GGT, ALP and total protein levels for the first group on day 7 compared to day 0. Although decreases and increases were present for the second group as well, no statistically significant difference was observed.

Table 4. Changes in biochemical parameters of calves with cryptosporidiosis before and during the treatment.

\begin{tabular}{|c|c|c|c|c|}
\hline Parameter & $\begin{array}{c}\text { Day } 0 \\
\text { Mean } \pm \text { SEM }\end{array}$ & $\begin{array}{c}\text { Day } 7 \\
\text { Mean } \pm \text { SEM }\end{array}$ & $P^{1}$ & $P^{2}$ \\
\hline \multicolumn{5}{|l|}{ BUN (mg/dL) } \\
\hline Group $1(n=10)$ & $35.89 \pm 8.27$ & $15.89 \pm 1.50$ & $<0.05$ & \multirow{2}{*}{$>0.05$} \\
\hline Group $2(n=10)$ & $28.57 \pm 7.42$ & $19.29 \pm 3.02$ & $>0.05$ & \\
\hline \multicolumn{5}{|l|}{ Creatinine (mg/dL) } \\
\hline Group 1 (n = 10) & $1.44 \pm 0.13$ & $1.11 \pm 0.05$ & $<0.05$ & \multirow{2}{*}{$>0.05$} \\
\hline Group $2(n=10)$ & $1.40 \pm 0.14$ & $1.34 \pm 0.16$ & $>0.05$ & \\
\hline \multicolumn{5}{|l|}{$\mathrm{AST}(\mathrm{U} / \mathrm{L})$} \\
\hline Group $1(n=10)$ & $57.11 \pm 17.88$ & $32.89 \pm 2.06$ & $>0.05$ & \multirow{2}{*}{$<0.05$} \\
\hline Group $2(n=10)$ & $44.71 \pm 6.24$ & $48.71 \pm 4.23$ & $>0.05$ & \\
\hline \multicolumn{5}{|l|}{ GGT (U/L) } \\
\hline Group $1(\mathrm{n}=10)$ & $101.22 \pm 24.72$ & $42.11 \pm 8.06$ & $<0.05$ & \multirow{2}{*}{$>0.05$} \\
\hline Group $2(n=10)$ & $119.43 \pm 34.44$ & $68.71 \pm 16.62$ & $>0.05$ & \\
\hline \multicolumn{5}{|l|}{ ALP $(\mathrm{U} / \mathrm{L})$} \\
\hline Group $1(n=10)$ & $159.56 \pm 17.04$ & $101.56 \pm 9.71$ & $<0.05$ & \multirow{2}{*}{$<0.05$} \\
\hline Group $2(n=10)$ & $96.43 \pm 10.73$ & $89.14 \pm 5.94$ & $>0.05$ & \\
\hline \multicolumn{5}{|l|}{ Total Protein (g/dL) } \\
\hline Group $1(n=10)$ & $5.78 \pm 0.42$ & $4.78 \pm 0.22$ & $<0.05$ & \multirow{2}{*}{$>0.05$} \\
\hline Group $2(n=10)$ & $5.19 \pm 0.34$ & $4.96 \pm 0.24$ & $>0.05$ & \\
\hline \multicolumn{5}{|l|}{ Albumin (g/dL) } \\
\hline Group $1(\mathrm{n}=10)$ & $3.55 \pm 0.14$ & $3.24 \pm 0.12$ & $>0.05$ & \multirow{2}{*}{$>0.05$} \\
\hline Group $2(n=10)$ & $3.34 \pm 0.15$ & $3.33 \pm 0.06$ & $>0.05$ & \\
\hline
\end{tabular}

BUN: blood urea nitrogen; AST: aspartate aminotransferase; GGT: gamma glutamyl transferase; ALP: alkaline phosphatase. $P^{\mathrm{l}}=$ Statistically significant $P$ value within groups; $P^{2}=$ Statistically significant $P$ value between groups.

\section{DISCUSSION}

Cryptosporidiosis is one of the most important problems among neonatal ruminants. $C$. parvum, the agent causing disease, has been reported to be one of the significant etiological agents of neonatal diarrhea seen in the first week of calves' life [2,24]. Cryptosporidium parvum infection, responsible for diarrhea, dehydration, weight loss and death (up to 50\%) in neonatal ruminants, leads to significant economic losses for producers [2]. Insufficient immunoglobulin intake in infected calves, prevalence of the disease, severity of diarrhea and involvement of other etiological agents are among the important reasons behind the increase in mortality [24]. Infected calves may exhibit clinical symptoms ranging from asymptomatic clinical findings to diarrhea and dehydration [26]. In this study, severe diarrhea, dehydration, depression and weight loss were observed in calves in both treatment groups (Figure 1). Diarrhea in calves leads to financial loss, and lost energy and time due to care, treatment (oral/ intravenous fluid therapy and drug administration) and hygienic measures $[2,19,26]$. Also, it has been reported 
that mortality increases due to other enteric pathogen (E. coli and rotavirus) infections seen simultaneously with $C$. parvum [24,25]. The most important problem related to cryptosporidiosis is the lack of an effective drug to prevent and treat the disease. In severe cryptosporidiosis outbreaks, it is absolutely essential to use anti-cryptosporidial drugs to control the disease.

Many pharmaceuticals or compounds have been tested for animal cryptosporidiosis and only very few of them have shown a partial protective activity in ruminants when used prophylactically. These can be listed as halofuginone lactate, paromomycin, cyclodextrins, azithromycin [18], nitazoxanide, activated charcoal and wood vinegar liquid [20,26,27,29].

Halofuginone lactate and paromomycin are commonly recommended as both therapeutic and protective agents. However, the effectiveness of the two therapeutic agents in natural infections has not been compared and, in the meantime, recommendations for a rational use are also not sufficiently documented in calves with cryptosporidiosis.

Paromomycin is an aminoglycoside antibiotic used to control $C$. parvum infection in animals $[12,16,28]$. Paromomycin reduces oocyst shedding and the number of days with diarrhea in experimentally infected calves when used prophylactically [5]. In this study, it was observed that the severity of diarrhea started to decrease from the second day of paromomycin use, clinical findings related to cryptosporidiosis improved and post-treatment hematological, serum biochemical and blood gas findings returned to normal values (Figure 1, Tables 2-4). It has been reported that paromomycin administration (at $100 \mathrm{mg} \mathrm{kg}^{-1}$ ) for 11 consecutive days beginning 1 day before oral inoculation stops oocyst shedding and reduces severity of diarrhea, whereas oocyst shedding begins at or near the end of paromomycin administration at a dose of $25 \mathrm{mg} \mathrm{kg}^{-1}$ or $50 \mathrm{mg} \mathrm{kg}^{-1}$ [5]. It has been stated that daily oral administration of paromomycin at $100 \mathrm{mg} \mathrm{kg}^{-1}$ for 21 days from birth has a prophylactic value for goats in a natural cryptosporidiosis outbreak [12]. The same dose of paromomycin has been found to be effective in both experimentally [28] and naturally [1] infected goats. Paromomycin has been found to reduce both oocyst output and severity of clinical symptoms in lambs when administered at $100 \mathrm{mg} \mathrm{kg}^{-1}$ per day for three consecutive days and at $200 \mathrm{mg} \mathrm{kg}^{-1}$ per day for two days [28]. In this study, on the other hand, although paromomycin administration at $100 \mathrm{mg} /$ $\mathrm{kg} /$ day led to a decrease in oocyst shedding from day 1 (Figure 2$)$, a statistically significant decrease $(P<0.05)$ was observed from day 3 (Figure 2).

Halofuginone lactate is a synthetic quinazolinone with cryptosporidial activity in the merozoite and sporozoite stages of $C$. parvum [10]. It is recommended for both therapeutic and prophylactic use in cryptosporidiosis. It has been reported that halofuginone lactate use reduces the severity and mortality of cryptosporidiosis in calves [11]. In this study, clinical (Figure 1), hematological (Table 2), blood gas (Table 3 ) and biochemical (Table 4) findings in calves with cryptosporidiosis improved during the period following halofuginone lactate use. Clinical studies have shown that halofuginone has a cryptosporidial activity in the merozoite and sporozoite stages of $C$. parvum [10]. It has been reported that halofuginone lactate is an effective drug against cryptosporidiosis in calves [13,21], goats [22] and lambs [17]. Petermann et al. [22] have reported that halofuginone lactate administered at 100 $\mu \mathrm{g} \mathrm{kg}{ }^{-1}$ for 10 days reduces oocyst shedding, diarrhea and mortality in goats experimentally infected with cryptosporidiosis. Halofuginone lactate administration (60 and $120 \mu \mathrm{g} \mathrm{kg}^{-1}$ ) considerably reduces oocyst shedding during the clinical phase of the disease in calves experimentally infected with cryptosporidiosis [21]. In this study, although halofuginone lactate administration at $100 \mu \mathrm{g} / \mathrm{kg} / \mathrm{day}$ led to a decrease in oocyst shedding from day 1 (Figure 2), a statistically significant decrease $(P<0.05)$ was observed from day 3 (Figure 2), but severity of clinical findings significantly decreased $(P<0.05)$ from day 2.

The results of this study show that the decrease in oocyst shedding in both treatment groups, improvements in clinical findings and recoveries in hematologic, blood gas and serum biochemistry values are similar. Even though these drugs do not eliminate the infection, they decrease both the severity of diarrhea and contribute to recovery.

\section{CONCLUSIONS}

In conclusion, the results of this study indicated that halofuginone lactate $(100 \mu \mathrm{g} / \mathrm{kg} /$ day for 7 days $)$ and paromomycin $(100 \mathrm{mg} / \mathrm{kg} /$ day for 7 days $)$ were effective in the treatment of calves with cryptosporidiosis. Therefore, we recommend that both drugs should be used in the treatment of calves naturally infected with Cyptosporidium parvum. 
MANUFACTURERS

${ }^{1}$ Intervet Productions MSD. Igoville, France.

${ }^{2}$ Ceva Animal Science. Istanbul, Turkey.

${ }^{3}$ Melet Schlosing Laboratories. Osny, France.

${ }^{4}$ Instrumentation Laboratory Inc. Bedford, MA, USA.

${ }^{5}$ Mindray Bio-Medical Electronics Co., Ltd. Shenzhen, China.
Declaration of interest. The authors report no conflicts of interest. The authors alone are responsible for the content and writing of the paper.

\section{REFERENCES}

1 Chartier C., Mallereau M.P. \& Lenfant D. 1999. Halofuginone lactate in the control of cryptosporidiosis in neonate kids. Revue de Médecine Vétérinaire. 150(4): 341-346.

2 de Graaf D.C., Vanopdenbosch E., Ortega-Mora L.M., Abbassi H. \& Peeters J.E. 1999. A review of the importance of cryptosporidiosis in farm animals. International Journal for Parasitology. 29(8): 1269-1287.

3 de Waele V., Speybroeck N., Berkvens D., Mulcahy G. \& Murphy T.M. 2010. Control of cryptosporidiosis in neonatal calves: Use of halofuginone lactate in two different calf rearing systems. Preventive Veterinary Medicine. 96(3-4): 143-151.

4 Delafosse A., Chartier C., Dupuy M.C., Dumoulin M., Pors I. \& Paraud C. 2015. Cryptosporidium parvum infection and associated risk factors in dairy calves in western France. Preventive Veterinary Medicine. 118(4): 406-412.

5 Fayer R. \& Ellis W. 1993. Paromomycin is effective as prophylaxis for cryptosporidiosis in dairy calves. Journal of Parasitology. 79(5): 771-774.

6 Foster D.M. \& Smith G.W. 2009. Pathophysiology of diarrhea in calves. Veterinary Clinics of North America: Food Animal Practice. 25(1): 13-36.

7 Garro C.J., Morici G.E., Utges M.E., Tomazic M.L. \& Schnittger L. 2016. Prevalence and risk factors for shedding of Cryptosporidium spp. oocysts in dairy calves of Buenos Aires Province, Argentina. Parasite Epidemiology and Control. 1(2): 36-41.

8 Heit M.C. \& Riviere J.E. 2001. Chemotherapy of Microbial Diseases. In: Adams H.R. (Ed). Veterinary Pharmacology and Therapeutics. 8th edn. Ames: Blackwell publishing, pp.783-946.

9 House J.K. \& Gunn A.A. 2009. Manifestations and management of disease in neonatal ruminants. In: Smith B.P. (Ed). Large Animal Internal Medicine. 4th edn. St. Louis Mosby Elsevier, pp.333-366.

10 Jarvie B.D., Trotz-Williams L.A., McKnight D.R., Leslie K.E., Wallace M.M., Todd C.G., Sharpe P.H. \& Peregrine A.S. 2005. Effect of halofuginone lactate on the occurrence of Cryptosporidium parvum and growth of neonatal dairy calves. Journal of Dairy Science. 88(5): 1801-1806.

11 Joachim A., Krull T., Schwarzkopf J. \& Daugschies A. 2003. Prevalence and control of bovine cryptosporidiosis in German dairy herds. Veterinary Parasitology. 112(4): 277-288.

12 Johnson E.H., Windsor J.J., Muirhead D.E., King G.J. \& Al-Busaidy R. 2000. Confirmation of the prophylactic value of paromomycin in a natural outbreak of caprine cryptosporidiosis. Veterinary Research Communications. 24(1): 63-67.

13 Keidela J. \& Daugschies A. 2013. Integration of halofuginone lactate treatment and disinfection with p-chloro-mcresol to control natural cryptosporidiosis in calves. Veterinary Parasitology. 196(3-4): 321-326.

14 Klein P. 2008. Preventive and therapeutic efficacy of halofuginone-lactate against Cryptosporidium parvum in spontaneously infected calves: A centralised, randomised, double-blind, placebo-controlled study. The Veterinary Journal. 177(3): 429-431.

15 Mancassola R., Reperant J.M., Naciri M. \& Chartier C. 1995. Chemoprophylaxis of Cryptosporidium parvum infection with paromomycin in kids and immunological study. Antimicrobial Agents and Chemotherapy. 39(1): 75-78.

16 Masood S., Maqbool A., Khan U.J., Chaudhry Z.I. \& Anjum A.A. 2013. Anti-Cryptosporidium activity of albendazole, metronidazole and paromomycin in experimentally infected cattle. Pakistan Journal of Zoology. 45(4): 935-940.

17 Naciri N., Bareille S., Fournier R. \& Holland W.G. 2005. Use of halofuginone in the control of Cryptosporidium parvum infections in sheep. In: 6th International Sheep Veterinary Congress (Crete, Greece). pp.257-258.

18 Nasir A., Avais M., Khan M.S., Khan J.A., Hameed S. \& Reichel M.P. 2013. Treating Cryptosporidium parvum infection in calves. Journal of Parasitology. 99(4): 715-717. 
19 Noordeen F., Rajapakse R.P.V.J., Horadagoda N.U., Abdul-Careem M.F. \& Arulkanthan A. 2012. Cryptosporidium, an important enteric pathogen in goats-A review. Small Ruminant Research. 106(2-3): 77-82.

20 Paraud C. \& Chartier C. 2012. Cryptosporidiosis in small ruminants. Small Ruminant Research. 103(1): 93-97.

21 Peeters J.E., Villacorta I., Naciri M. \& Vanopdenbosch E. 1993. Specific serum and local antibody responses against Cryptosporidium parvum during medication of calves with halofuginone lactate. Infection and Immunity. 61(10): 44404445.

22 Petermann J., Paraud C., Pors I. \& Chartier C. 2014. Efficacy of halofuginone lactate against experimental cryptosporidiosis in goat neonates. Veterinary Parasitology. 202(3-4): 326-329.

23 Pines M. \& Nagler A. 1998. Halofuginone: A novel antifibrotic therapy. General Pharmacology. 30(4): $445-450$.

24 Radostits O.M., Gay C.C., Hinchcliff K.W. \& Constable P.D. 2007. Veterinary Medicine: A textbook of the diseases of cattle, sheep, goats, pigs and horses. 10th edn. London: Saunders Elsevier, pp.1483-1540.

25 Santin M. 2013. Clinical and subclinical infections with Cryptosporidium in animals. The New Zealand Veterinary Journal. 61(1): 1-10.

26 Shahiduzzaman M. \& Daugschies A. 2012. Therapy and prevention of cryptosporidiosis in animals. Veterinary Parasitology. 188(3-4): 203-214.

27 Villacorta I., Peeters J.E. \& Vanopdenbosch E. 1991. Efficacy of halofuginone lactate against Cryptosporidium parvum in calves. Antimicrobial Agents and Chemotherapy. 35(2): 283-287.

28 Viu M., Quilez J., Sánchez-Acedo C., del Cacho E. \& López-Bernad F. 2000. Field trial on the therapeutic efficacy of paromomycin on natural Cryptosporidium parvum infections in lambs. Veterinary Parasitology. 90(3): 163-170.

29 Watarai S., Tana. \& Koiwa M. 2008. Feeding activated charcoal from bark containing wood vinegar liquid (nekkarich) is effective as treatment for cryptosporidiosis in calves. Journal of Dairy Science. 91(4): 1458-1463. 